\title{
Implantation of intracorneal ring segments in pediatric patients: long-term follow-up
}

This article was published in the following Dove Press journal: International Medical Case Reports Journal

\author{
Ana Carolina Abreu' \\ Luisa Malheiro' \\ João Coelho' \\ Miguel Mesquita Neves' \\ Miguel Gomes 1,2 \\ Luis Oliveira ${ }^{1,2}$ \\ Pedro Menéres ${ }^{1,2}$ \\ 'Ophthalmology Department of \\ Hospital de Santo António - Centro \\ Hospitalar do Porto, Porto, Portugal; \\ ${ }^{2}$ Ophthalmology Department, \\ Instituto de Ciências Biomédicas Abel \\ Salazar (ICBAS) - Universidade do \\ Porto, Porto, Portugal
}

Purpose: To analyze the long-term outcomes of intracorneal ring segments (ICRS) implantation for keratoconus management in pediatric patients.

Methods: Retrospective case series review of the long-term ( $>5$ years) outcomes of Intacs ${ }^{\circledR}$ ICRS implantation for keratoconus in pediatric patients (age $<18$ years old at the time of surgery) between January 2008 and December 2011 at Ophthalmology Department of Hospital de Santo António. Demographic data, follow-up time, preoperative and postoperative uncorrected visual acuity (UCVA) and best-corrected visual acuity (BCVA) in decimal scale, and corneal topography were evaluated. Statistical analysis was done using SPSS for windows (version 24). Significance was set at $p<0.0125$. Results: Fourteen eyes of 14 patients, with a mean age of 15.36 years (range 10-18 years), were included in this study. All patients had been diagnosed with keratoconus with reported progression in the 6 months prior to surgery. Follow-up time was $6.36 \pm 0.97$ years. UCVA and BCVA improved after ICRS implantation $(p<0.0125)$. Keratometry $(\mathrm{K})$ minimum $(\mathrm{Kmin})$ and $\mathrm{K}$ maximum (Kmax) decreased after surgery $(p<0.0125)$. During follow-up, UCVA, BCVA, Kmin, and Kmax values ranged, showing a tendency to worsen at the end of follow-up. However, statistically significant differences were not observed.

Conclusion: ICRS implantation showed good visual and topographic results in pediatric patients. Long-term follow-up suggests that, despite ICRS implantation, there is still progression of keratoconus. To the best of our knowledge, there are no reports regarding the long-term efficacy of ICRS implantation in pediatric patients.

Keywords: intracorneal ring segments, keratoconus, pediatric patients

\section{Introduction}

Classically, keratoconus is a bilateral, corneal, ectatic noninflammatory condition, the hallmark of which is progressive corneal steepening and thinning, ${ }^{1}$ which leads to irregular astigmatism and secondary loss of best-corrected visual acuity (BCVA). The onset of keratoconus is common during the second decade of life, with great variability in progression, which may last until the third or fourth decade of life. ${ }^{2}$ Keratoconus behaves differently in pediatric patients, presenting a more aggressive course in this age group. There is no gender predominance; however, affected younger patients are more often males. ${ }^{3}$

The treatment for keratoconus should be personalized, depending on the severity of disease, the amount of vision loss, the progression rate, and the psychosocial aspect of the patient. The therapeutic options can vary from eyeglasses and contact lenses to intracorneal ring segments (ICRS) implantation, corneal transplantation,
Correspondence: Ana Carolina Abreu Ophthalmology Department of Hospital de Santo António - Centro Hospitalar do Porto, Largo Prof. Abel Salazar 4099-00I Porto, Portugal

Tel +35I 918292207

Email carolina.abreu88mail.com
International Medical Case Reports Journal 2018: I $23-27$

Dovepress in

(c) (i) (5) 2018 Abreu et al. This work is published and licensed by Dove Medical Press Limited. The full terms of this license are available at https://www.dovepress.com/terms. (c) BY you hereby accept the Terms. Non-commercial uses of the work are permitted without any further permission from Dove Medical Press Limited, provided the work is properly attributed. For permission for commercial use of this work, please see paragraphs 4.2 and 5 of our Terms (https://www.dovepress.com/terms.php). 
and cross-linking associated or not with photorefractive keratectomy. ${ }^{4}$ The traditional conservative management of keratoconus begins with eyeglasses correction and contact lenses. ${ }^{5,6}$ When vision can no longer be corrected with eyeglasses and/or contact lenses, surgical options should be considered. ${ }^{1}$ ICRS are small devices of synthetic material which can be used to reshape the abnormal cornea, inducing a geometric change of central curvature. This leads to an improvement in topographic abnormalities, reducing refractive error, and improving visual acuity. 6,7 Classically, the goal of segment implantation is to delay or avoid corneal grafts. ${ }^{8}$ There are many types of ICRS devices. Intacs $^{\circledR}$ (Addition Technology Inc., Fremont, CA, USA) are semicircular pieces of polymethyl methacrylate (PMMA) with fixed outer diameter and width, available in different thicknesses. There is an additional Intacs design named severe keratoconus (SK) designed with rounded edges to potentially reduce the incidence of visual symptoms. Ferrara $^{\circledR}$ and Keraring ${ }^{\circledR}$ are other types of ICRS commonly used to treat corneal ectatic diseases.

Many studies report the efficacy of ICRS implantation in the treatment of keratoconus, including long-term follow-up (superior to 5 years). ${ }^{9-13}$ Some studies suggested that this surgical treatment has the potential to halt the progression of keratoconus, but there is still no definitive scientific evidence to confirm that. ${ }^{11-13}$

To the best of our knowledge, there are no reports regarding the long-term efficacy of ICRS implantation in pediatric patients. The purpose of this study is to report long-term follow-up of ICRS implantation in pediatric population in the management of keratoconus.

\section{Methods}

Retrospective review of the medical records of patients with keratoconus submitted for ICRS implantation in pediatric patients, between January 2008 and December 2011, to Ophthalmology Department of Centro Hospitalar do Porto, Oporto, Portugal, was performed. This study included only patients who completed at least 5 years of follow-up. Patients were excluded from ICRS implantation if any of the following criteria was present: advanced keratoconus with curvatures $>60.0$ diopters (D) and significant apical opacities or scaring, previous hydrops, corneal thickness $<400 \mu \mathrm{m}$ in the planned site of ICRS implantation, and intense atopia. These are the criteria used, in our department, to define candidates not suitable for ICRS implantation. When both eyes of the same patient met the inclusion criteria, it was decided to include only one eye for statistical analysis. In these cases, we chose to randomly select one of the eyes as recommended by Statistical Guidelines for the analysis of data obtained from one or both eyes. ${ }^{14}$

This study was approved by the local ethics committee of Centro Hospitalar do Porto, EPE. All patients provided informed consent to use their medical records.

In these patients, Intacs and Intacs SK (Addition Technology Inc.) ICRS were used. The surgeries were performed by three corneal surgeons, using a standard technique of tunnel creation by mechanical dissection. ICRS were implanted according to a preoperative plan and an implantation nomogram provided by the manufacturers of Intacs ICRS.

The demographic data, follow-up time, preoperative and postoperative uncorrected visual acuity (UCVA) and BCVA in decimal scale were evaluated. Corneal topography and thickness were obtained at preoperative visit and at 6-12 months, 24-36 months, and at the last visit ( $\geq 5$ years postoperative) using the Bausch \& Lomb’s Orbscan ${ }^{\circledR}$ IIz.

Statistical analysis was done using SPSS for windows (version 24; SPSS Inc., Chicago, IL, USA). After checking the normality of data using the Shapiro-Wilk test, the Wilcoxon rank-sum test was used to compare preoperative and postoperative parameters. As the analysis was performed at four time points, the Bonferroni correction was applied. Therefore, statistical significance was established at $p<0.0125$ (two-sided).

\section{Results}

Fourteen eyes of 14 patients were included in this study. The mean age of patients at the time of surgery was $15.36 \pm 2.84$ years (range $10-18$ years old), with $64.3 \%$ being males and $35.7 \%$ females. All patients had been diagnosed with keratoconus with reported progression in the 6 months prior to surgery. All procedures were uneventful. Intacs SK were implanted in four eyes, while conventional Intacs were used in 10 eyes (Figure 1). In seven eyes, single-segment Intacs were implanted. Follow-up time was $6.36 \pm 0.97$ years.

In one case, ICRS extrusion occurred 7 months after surgery spontaneously. As the patient remained with satisfactory visual acuity (BCVA 0.6 in decimal scale) and no significant progression was observed, corneal transplantation was not performed. During the considered follow-up, there were no other complications to report.

Baseline average UCVA and BCVA were $0.07 \pm 0.09$ and $0.34 \pm 0.21$, respectively, and they improved to $0.25 \pm 0.15$ and $0.54 \pm 0.17$ after ICRS implantation $(p<0.01$ and $p=0.011$, respectively). During follow-up, both UCVA and BCVA 
remained almost constant, reaching, at the end of follow-up, $0.3 \pm 0.21$ and $0.55 \pm 0.13$ without statistically significant differences from those observed at 6-12 months postoperatively, (Tables 1 and 2).

Central corneal thickness remained stable after the surgery, ranging from $416.43 \pm 47.38$ to $409.75 \pm 54 \mu \mathrm{m}$ 6-12 months after surgery $(p=0.14) . \mathrm{K}$ minimum $(\mathrm{Kmin})$ decreased from $48.9 \pm 3.25$ to $45.29 \pm 3.45 \mathrm{D}(p=0.001)$ and $\mathrm{K}$ maximum (Kmax) reduced from $55.92 \pm 4.56$ to $51.4 \pm 3.33$ $\mathrm{D}(p=0.002) 6-12$ months after surgery. During follow-up, Kmin and Kmax values ranged (Table 1), showing a tendency to increase at the end of follow-up. However, statistically significant differences were not observed (Table 3 ).

Until the end of follow-up, no patient needed additional procedures, besides the use of optical correction with glasses or contact lenses.

\section{Discussion}

Keratoconus typically presents in teenagers and progresses until the third or fourth decade. ${ }^{2}$ The disease behavior is different in pediatric patients when compared with adults, since it may present at more aggressive stage and progress more rapidly. ${ }^{3,15}$ These aspects make the disease management in this age very challenging. Contact lenses may not be well tolerated and, despite the introduction of lamellar transplantation techniques and the better visual outcomes and graft survival in patients with keratoconus than in grafts performed for other indications, corneal transplantation in pediatric patients can be associated with higher incidence of complications. ${ }^{16-18}$ Treatments such as corneal collagen cross-linking and ICRS should be considered in this age. In a meta-analysis, McAnena et al showed that standard corneal collagen cross-linking seems to be effective in halting the progression of keratoconus in pediatric patients. ${ }^{19}$ However, concerning ICRS implantation in these population, studies are lacking. Although some studies included younger patients and some suggested that they can halt the progression of keratoconus, the authors found no study including only pediatric patients or patients $<15$ years. These are the reasons why, in our study, we intended to evaluate the long-term outcomes of ICRS implantation in pediatric patients.

Since the first report of ICRS implantation outcomes for the treatment of keratoconus, several authors have demonstrated the efficacy of this technique in improving keratometric readings in this disease. ICRS implantation leads to a flattening of the central cornea and regularization of the asymmetry of the tissue, resulting in a reduction of keratometric readings, with a mean reduction between 3 and $5 \mathrm{D} .{ }^{20-23}$ In addition, the majority of these studies report a gain in both the uncorrected and best-corrected visual acuities. Similar to the cited studies, in our study we observed an improvement of keratometric values, UCVA, and BCVA after ICRS implantation. Kmax and Kmin decreased, on average,
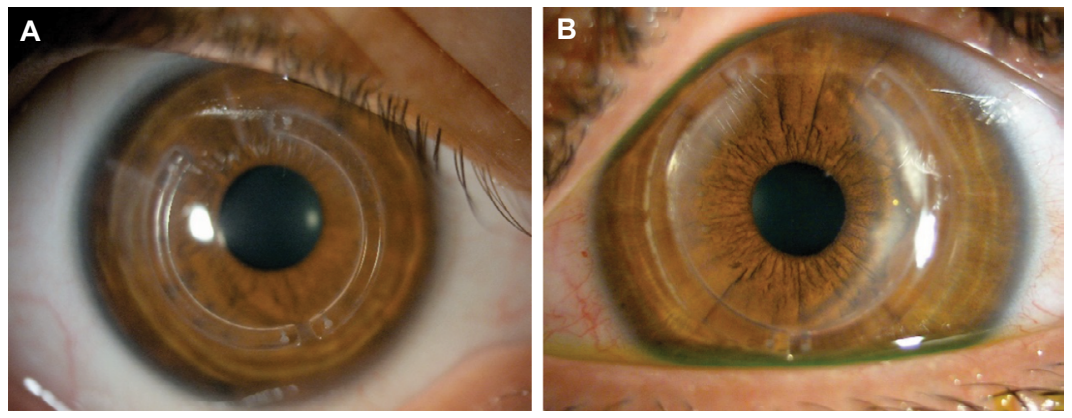

Figure I Implanted ICRS at the end of follow-up.

Notes: (A) Implanted Intacs ${ }^{\circledR}$ ICRS. (B) Implanted Intacs SK ICRS.

Abbreviations: ICRS, intracorneal ring segments; SK, severe keratoconus.

Table I Visual outcomes and keratometry readings before and after ICRS implantation

\begin{tabular}{|c|c|c|c|c|}
\hline Variable & Preoperative & $\begin{array}{l}\text { 6-12 months } \\
\text { postoperative }\end{array}$ & $\begin{array}{l}\text { 24-36 months } \\
\text { postoperative }\end{array}$ & $\begin{array}{l}>60 \text { months } \\
\text { postoperative }\end{array}$ \\
\hline UCVA (range) & $0.07 \pm 0.09(0.01-0.32)$ & $0.25 \pm 0.15(0.05-0.5)$ & $0.3 \pm 0.2(0.05-0.5)$ & $0.3 \pm 0.21(0.05-0.5)$ \\
\hline BCVA (range) & $0.34 \pm 0.21(0.05-0.63)$ & $0.54 \pm 0.17(0.3-0.8)$ & $0.56 \pm 0.1(0.4-0.8)$ & $0.55 \pm 0.13(0.4-0.8)$ \\
\hline Central corneal thickness $(\mu \mathrm{m})$, range & $416.43 \pm 47.38(335-494)$ & $409.75 \pm 54(356-472)$ & $410.45 \pm 43.44(335-475)$ & $412.56 \pm 47.18(338-485)$ \\
\hline $\mathrm{K}$ minimum (D) (range) & $48.9 \pm 3.25(43.2-52.9)$ & $45.29 \pm 3.45(37.4-51.4)$ & $46.34 \pm 3.45(38.2-51.3)$ & $46.38 \pm 3.42(38-51.4)$ \\
\hline $\mathrm{K}$ maximum (D) (range) & $55.92 \pm 4.56(47.5-62.4)$ & $51.4 \pm 3.33(46.7-56.8)$ & $51.65 \pm 3.71(46.4-56.0)$ & $52.19 \pm 3.60(47.3-57.2)$ \\
\hline
\end{tabular}

Abbreviations: BCVA, best-corrected visual acuity; D, diopters; ICRS, intracorneal ring segments; K, keratometry; UCVA, uncorrected visual acuity. 
Table 2 Visual outcomes during follow-up

\begin{tabular}{llll}
\hline Variable & Compared period & Compared values & $p$-value \\
\hline UCVA & Preoperative vs 6-12 months postoperative & $0.07 \pm 0.09$ vs $0.25 \pm 0.15$ & 0.008 \\
& Preoperative vs $>60$ months postoperative & $0.07 \pm 0.09$ vs $0.3 \pm 0.21$ & 0.009 \\
& 6-12 months vs $24-36$ months postoperative & $0.25 \pm 0.15$ vs $0.3 \pm 0.2$ & 0.115 \\
& $24-36$ months vs $>60$ months postoperative & $0.3 \pm 0.2$ vs $0.3 \pm 0.21$ & 0.970 \\
BCVA & 6-12 months vs $>60$ months postoperative & $0.25 \pm 0.15$ vs $0.3 \pm 0.21$ & 0.115 \\
& Preoperative vs 6-12 months postoperative & $0.34 \pm 0.21$ vs $0.54 \pm 0.17$ & 0.011 \\
& Preoperative vs $>60$ months postoperative & $0.34 \pm 0.21$ vs $0.55 \pm 0.13$ & 0.010 \\
& 6-12 months vs $24-36$ months postoperative & $0.54 \pm 0.17$ vs $0.56 \pm 0.1$ & 0.831 \\
& 24-36 months vs $>60$ months postoperative & $0.56 \pm 0.1$ vs $0.55 \pm 0.13$ & 0.986 \\
\hline
\end{tabular}

Abbreviations: BCVA, best-corrected visual acuity; UCVA, uncorrected visual acuity.

Table 3 Keratometry changes after ICRS implantation

\begin{tabular}{|c|c|c|c|}
\hline Variable & Compared period & Compared values & p-value \\
\hline \multirow[t]{5}{*}{ K Maximum } & Preoperative vs $6-12$ months postoperative & $55.92 \pm 4.56$ vs $51.4 \pm 3.33$ & 0.002 \\
\hline & Preoperative vs $>60$ months postoperative & $55.92 \pm 4.56$ vs $52.19 \pm 3.60$ & 0.004 \\
\hline & $6-12$ months vs $24-36$ months postoperative & $51.4 \pm 3.33$ vs $51.65 \pm 3.71$ & 0.504 \\
\hline & $24-36$ months vs $>60$ months postoperative & $51.65 \pm 3.71$ vs $52.19 \pm 3.60$ & 0.058 \\
\hline & $6-12$ months vs $>60$ months postoperative & $51.4 \pm 3.33$ vs $52.19 \pm 3.60$ & 0.074 \\
\hline \multirow[t]{5}{*}{ K Minimum } & Preoperative vs $6-12$ months postoperative & $48.9 \pm 3.25$ vs $45.29 \pm 3.45$ & 0.001 \\
\hline & Preoperative vs $>60$ months postoperative & $48.9 \pm 3.25$ vs $46.38 \pm 3.42$ & 0.003 \\
\hline & $6-12$ months vs $24-36$ months postoperative & $45.29 \pm 3.45$ vs $46.34 \pm 3.45$ & 0.053 \\
\hline & $24-36$ months vs $>60$ months postoperative & $46.34 \pm 3.45$ vs $46.38 \pm 3.42$ & 0.317 \\
\hline & $6-12$ months vs $>60$ months postoperative & $45.29 \pm 3.45$ vs $46.38 \pm 3.42$ & 0.052 \\
\hline
\end{tabular}

Abbreviations: ICRS, intracorneal ring segments; K, keratometry.

3.59 and $3.18 \mathrm{D}$, respectively, which agree with the values observed in previous studies.

As noted earlier, in our patients we used Intacs ICRS, both conventional and SK. We did not analyze differences between these two devices since we had a small sample and previous reports showed that implantation of conventional and SK Intacs had comparable outcomes. ${ }^{24,25}$ Also, we did not study differences between using single- or doublesegment implantation. In literature, some authors claim that single-segment implantation provides better results, ${ }^{26}$ while others claim that the results vary with topographic pattern of keratoconus ${ }^{27}$ or with spherical equivalent to correct. ${ }^{28,29}$ As there are several factors that can influence the selection of one or two segments and since our sample is small, we decided not to evaluate these outcomes.

In the matter of the stability of the results of ICRS implantation in long-term follow-up, we found contradictory results in the literature. While some authors report long-term stability of surgical results, Vega-Estrada et al ${ }^{23,30}$ and Alió et al ${ }^{31}$ observed that the long-term stability of ICRS implantation depends on the progression pattern of keratoconus at the time of surgery, suggesting that in cases of stable keratoconus the results remained stable, in opposition to progressive disease where the short-term outcomes could change after a long period of time. In our study, we observed, in fact, changes in keratometric readings over time. However, these differences were not statistically significant. In our study, the fact that, the included patients were aged between 10 and 18 years with a great temporal edge of disease progression may be the reason for not getting statistically significant differences in keratometric readings over time. Regarding visual acuity, we observed maintenance of the visual gains achieved with ICRS implantation. Thus, once our results suggest that ICRS implantation does not halt progression of keratoconus over time, it is important to consider the use of alternative treatments or combination of different treatment modalities in the management of pediatric keratoconus.

\section{Conclusion}

ICRS implantation shows good visual and topographic results in pediatric patients. Although not statically significant, long-term follow-up of these patients suggests that ICRS implantation does not halt the progression of keratoconus.

To the best of the authors' knowledge, this is the first study that evaluates the effect of ICRS implantation in such young patients and with such a long follow-up. 


\section{Disclosure}

The authors report no conflicts of interest in this work.

\section{References}

1. American Academy of Ophthalmology Cornea/External Disease Panel Preferred Practice Pattern ${ }^{\circledR}$ Guidelines. Corneal Ectasia. San Francisco, CA: American Academy of Ophthalmology; 2013.

2. Rabinowitz YS. Keratoconus. Surv Ophthalmol. 1998;42(4):297-319.

3. Léoni-Mesplié S, Mortemousque B, Mesplié N, et al. Epidemiological aspects of keratoconus in children. J Fr Ophthalmol. 2012; 35(10):776-785.

4. Andreanos KD, Hashemi K, Petrelli M, Droutsas K, Georgalas I, Kymionis GD. Keratoconus treatment algorithm. Ophthalmol Ther. 2017;6(2):245-262.

5. Dalton K, Sorbara L. Fitting an MSD (Mini Scleral Design) rigid contact lens in advanced keratoconus with INTACS. Cont Lens Anterior Eye. 2011;34(6):274-281.

6. Espandar L, Meyer J. Keratoconus: overview and update on treatment. Middle East Afr J Ophthalmol. 2010;17(1):15-20.

7. Torquetti L, Berbel RF, Ferrara P. Long-term follow-up of intrastromal corneal ring segments in keratoconus. J Cataract Refract Surg. 2009;35(10):1768-1773.

8. Zare MA, Hashemi H, Salari MR. Intracorneal ring segment implantation for the management of keratoconus: safety and efficacy. J Cataract Refract Surg. 2007;33(11):1886-1891.

9. Bedi R, Touboul D, Pinsard L, Colin J. Refractive and topographic stability of Intacs in eyes with progressive keratoconus: five-year follow-up J Refract Surg. 2012;28(6):392-396.

10. Kyomionis GD, Siganos CS, Tsiklis NS, et al. Long-term follow-up of Intacs in keratoconus. Am J Ophthalmol. 2007;143(2):236-244.

11. Torquetti L, Berbel RF, Ferrara P. Long-term follow-up of intrastromal corneal ring segments in keratoconus. J Cataract Refract Surg. 2009;35(10):1768-1773.

12. Pesando PM, Ghiringhello MP, Di Meglio G, Romeo S. Treatment of keratoconus with ferrara ICRS and consideration of the efficacy of the ferrara nomogram in a 5-year follow-up. Eur J Ophthalmol. 2010;20(5):865-873.

13. Vega-Estrada A, Alió JL, Brenner LF, Burguera N. Outcomes of intracorneal ring segments for the treatment of keratoconus: five years follow-up analysis. J Cataract Refract Surg. 2013;39(8):1234-1240.

14. Armstrong RA. Statistical guidelines for the analysis of data obtained from one or both eyes. Ophthalmic Physiol Opt. 2013;33(1):7-14

15. Chatzis N, Hafezi F. Progression of keratoconus and efficacy of pediatric (corrected) corneal collagen cross-linking in children and adolescents. $J$ Refract Surg. 2012;28(11):753-758.

16. Lowe MT, Keane MC, Coster DJ, Williams KA. The outcome of corneal transplantation in infants, children, and adolescents. Ophthalmology. $2011 ; 118(3): 492-497$.
17. Kelly TL, Williams KA, Coster DJ; Australian Corneal Graft Registry. Corneal transplantation for keratoconus: a registry study. Arch Ophthalmol. 2011;129(6):691-697.

18. Gabrić N, Dekaris I, Vojniković B, Karaman Z, Mravicić I, Katusić J. Corneal transplantation in children. Coll Antropol. 2001;25(1): $17-22$.

19. McAnena L, Doyle F, O'Keefe M. Cross-linking in children with keratoconus: a systematic review and meta-analysis. Acta Ophthalmol. 2017;95(3):229-239.

20. Piñero DP, Alió JL. Intracorneal ring segments in ectatic corneal disease - a review. Clin Exp Ophthalmol. 2010;38(2):154-167.

21. Coskunseven E, Kymionis GD, Tsiklis NS, et al. One-year results of intrastromal corneal ring segment implantation (KeraRing) using femtosecond laser in patients with keratoconus. Am J Ophthalmol. 2008;145(5):775-779.

22. Alió JL, Shabayek MH, Belda JI, Correas P, Feijoo ED. Analysis of results related to good and bad outcomes of Intacs implantation for keratoconus correction. J Cataract Refract Surg. 2006;32(5): 756-761.

23. Vega-Estrada A, Alio JL, Brenner LF, et al. Outcome analysis of intracorneal ring segments for the treatment of keratoconus based on visual, refractive, and aberrometric impairment. Am J Ophthalmol. 2013;155(3):575-584.e1.

24. Hashemian MN, Zare MA, Mohammadpour M, Rahimi F, Fallah MR, Panah FK. Outcomes of single segment implantation of conventional Intacs vs Intacs SK for Keratoconus. J Ophthalmic Vis Res. 2014;9(3): 305-309.

25. Al Muammar A. Comparison of visual, refractive and topographic keratometry outcomes of Intacs and Intacs SK in mild to moderate keratoconus eyes. Middle East Afr J Ophthalmol. 2015;22(1):74-79.

26. Sharma M, Boxer Wachler BS. Comparison of single segment and double-segment Intacs for keratoconus and post-LASIK ectasia. Am J Ophthalmol. 2006;141(5):891-895.

27. Alió JL, Artola A, Hassanein A, Haroun H, Galal A. One or 2 Intacs segments for the correction of keratoconus. J Cataract Refract Surg. 2005;31(5):943-953.

28. Miranda D, Sartori M, Francesconi C, Allemann N, Ferrara P, Campos M. Ferrara intrastromal corneal ring segments for severe keratoconus. J Refract Surg. 2003;19(6):645-653.

29. Siganos D, Ferrara P, Chatzinikolas K, Bessis N, Papastergiou G. Ferrara intrastromal corneal rings for the correction of keratoconus. J Cataract Refract Surg. 2002;28(11):1947-1951.

30. Vega-Estrada A, Alió JL, Plaza Puche AB. Keratoconus progression after intrastromal corneal ring segment implantation in young patients: Five year follow-up. J Cataract Refrc Surg. 2015;41(6):1145-1152.

31. Alió JL, Vega-Estrada A, Esperanza S, Barraquer RI, Teus MA, Murta J. Intrastromal corneal ring segments: how successful is the surgical treatment of keratoconus? Middle East Afr J Ophthalmol. 2014; 21(1):3-9.
International Medical Case Reports Journal

\section{Publish your work in this journal}

The International Medical Case Reports Journal is an international, peer-reviewed open-access journal publishing original case reports from all medical specialties. Previously unpublished medical posters are also accepted relating to any area of clinical or preclinical science. Submissions should not normally exceed 2,000 words or
Dovepress

4 published pages including figures, diagrams and references. The manuscript management system is completely online and includes a very quick and fair peer-review system, which is all easy to use. Visit http://www.dovepress.com/testimonials.php to read real quotes from published authors. 